\title{
Socioeconomic differences in caesarean section - are they explained by medical need? An analysis of patient record data of a large Kenyan hospital
}

Lisa van der Spek ${ }^{1 \dagger}$, Sterre Sanglier ${ }^{1 \dagger}$, Hillary M. Mabeya ${ }^{2}$, Thomas van den Akker ${ }^{3,4}$, Paul L. J. M. Mertens ${ }^{1,5}$ and Tanja A. J. Houweling ${ }^{1 *+}$ (D)

\begin{abstract}
Background: Caesarean section (C-section) rates are often low among the poor and very high among the betteroff in low- and middle-income countries. We examined to what extent these differences are explained by medical need in an African context.

Methods: We analyzed electronic records of 12,209 women who gave birth in a teaching hospital in Kenya in 2014. C-section rates were calculated by socioeconomic position (SEP), using maternal occupation (professional, small business, housewife, student) as indicator. We assessed if women had documented clinical indications according to hospital guidelines and if socioeconomic differences in C-section rates were explained by indication.

Results: Indication for C-section according to hospital guidelines was more prevalent among professionals than housewives (16\% vs. 9\% of all births). The C-section rate was also higher among professionals than housewives (21.1\% vs. $15.8 \%$ [OR 1.43; 95\%Cl 1.23-1.65]). This C-section rate difference was largely explained by indication (4.7 of the 5.3 percentage point difference between professionals and housewives concerned indicated C-sections, often with previous C-section as indication). Repeat C-sections were near-universal (99\%). 43\% of primary C-sections had no documented indication. Over-use was somewhat higher among professionals than housewives (C-section rate among women without indication: 6.6 and 5.5\% respectively), which partly explained socioeconomic differences in primary $\mathrm{C}$-section rate.
\end{abstract}

Conclusions: Socioeconomic differences in C-section rates can be largely explained by unnecessary primary Csections and higher supposed need due to previous C-section. Prevention of unnecessary primary C-sections and promoting safe trial of labor should be priorities in addressing C-section over-use and reducing inequalities.

(Continued on next page)

\footnotetext{
* Correspondence: a.j.houweling@erasmusmc.nl

†Lisa van der Spek, Sterre Sanglier and Tanja A. J. Houweling contributed equally to this work.

'Department of Public Health, Erasmus MC, University Medical Center Rotterdam, Rotterdam, The Netherlands

Full list of author information is available at the end of the article
}

(C) The Author(s). 2020 Open Access This article is licensed under a Creative Commons Attribution 4.0 International License, which permits use, sharing, adaptation, distribution and reproduction in any medium or format, as long as you give appropriate credit to the original author(s) and the source, provide a link to the Creative Commons licence, and indicate if changes were made. The images or other third party material in this article are included in the article's Creative Commons. licence, unless indicated otherwise in a credit line to the material. If material is not included in the article's Creative Commons licence and your intended use is not permitted by statutory regulation or exceeds the permitted use, you will need to obtain permission directly from the copyright holder. To view a copy of this licence, visit http://creativecommons.org/licenses/by/4.0/ The Creative Commons Public Domain Dedication waiver (http://creativecommons.org/publicdomain/zero/1.0/) applies to the data made available in this article, unless otherwise stated in a credit line to the data. 
(Continued from previous page)

Tweetable abstract: Unnecessary primary C-sections and ubiquitous repeat C-sections drive overall C-section rates and C-section inequalities.

Keywords: Delivery, Caesarean section, Maternity services, Developing countries, Obstetrics and gynaecology, Epidemiology, General obstetric, Pregnancy, Health equity, Socioeconomic factors, Africa, Clinical category, General obstetrics

\section{Background}

Caesarean section (C-section) rates are rapidly rising in low and middle income countries [1] and can reach very high levels among women of higher socioeconomic position (SEP) [2]. At the same time, unmet need for Csection among poor women in these countries is usually high. While C-section rates remain low in most SubSaharan African countries, they are gradually increasing, and socioeconomic differences in C-section rates are substantial [3]. In Kenya, for example, the $\mathrm{C}$-section rate ranges from $2.4 \%$ in the poorest quintile to $19 \%$ in the richest quintile, as estimated from a nationally representative survey conducted in 2014 [4].

While the surgery can be life-saving when medically indicated, $\mathrm{C}$-section rates above $10 \%$ at the population level are not associated with improved maternal and newborn outcomes $[5,6]$. On the contrary, unnecessary $\mathrm{C}$-sections are associated with higher risks of adverse outcomes for woman and baby compared with vaginal birth $[7,8]$.

While socioeconomic inequalities in $\mathrm{C}$-section rates are well-documented, it remains unknown to what extent they can be explained by higher medical need among better-off women. Medical need for C-section might arguably differ between socioeconomic groups, for example due to differences in age and parity. Individuallevel data on clinical indication for C-section are often not available or accessible in low- and middle-income countries $[9,10]$, let alone in combination with information on socioeconomic position.

Our study aimed to address this paucity of evidence by describing and explaining socioeconomic inequalities in $\mathrm{C}$-section using clinical record data of an academic referral hospital in Kenya. Specifically, we aimed to examine clinical indications for $\mathrm{C}$-section and under- and over-use of $\mathrm{C}$-section across socioeconomic groups, and the role of medical need for $\mathrm{C}$-section in explaining socioeconomic inequalities in $\mathrm{C}$-section rates.

\section{Methods}

\section{Study setting}

Our study was conducted in the public wing of a large academic referral hospital in Kenya. The maternity department consisted of an antepartum ward ( 29 beds), labor ward (18 beds), postpartum ward ( 35 beds), neonatology unit (max. 160 beds), and a hostel (45 beds, 24-h observation of post-partum women without complications). Maternity care in the hospital, as in the rest of Kenya, was officially free as of June 1st, 2013.

\section{Study population and data collection}

All women who gave birth in the public wing of the hospital between 1 January and 31 December 2014 were included in our study. Excluded were births of fetuses with an estimated weight below $650 \mathrm{~g}$ (21 deliveries) because $\mathrm{C}$-sections were not performed in this hospital in these women. All women who gave birth at the hospital, were registered in an electronic Delivery Database after discharge. The Delivery Database contained a digitalized version of parts of the manual patient file that all women received, and included the following variables: patient number, admission date and time, discharge date, maternal age, parity, maternal occupation, ICD codes, multiple gestation, mode of birth, outcome mother, outcome infant, birth weight, name of ANC clinic the mother attended, referring facility, and reason for referral. Medical record officers digitalized the manual files and coded data according to the International Classification of Diseases and Related Health Problems 10th edition (ICD-10) and the International Classification of Procedures in Medicine [11, 12]. C-sections were also registered in a Surgery Database: a digitalized version of the Surgery Book, which contained all surgeries at the maternity department. We obtained anonymised versions of the Delivery Database and Surgery Database for our analyses. We linked the Delivery Database and Surgery Database on the basis of patient number, in combination with other variables in the databases where needed. To verify the accuracy of the electronic databases, we conducted a detailed review of a random selection of manual files (case notes). Hundred fifty women who gave birth (either vaginally or by CS) and 50 women who gave birth specifically by CS in MTRH in 2014 were randomly selected from the Delivery Database. For 131 (82 vaginal, 49 CS) out of the 200 women, we were able to retrieve the manual file. A detailed review of the manual files was done by LvdS and SS to assess whether or not women had a documented CS indication, using procedures described below.

\section{Definition of study outcome and determinants}

The study outcome was defined mode of birth (C-section vs. vaginal birth). Records were included as C- 
section if the Delivery Database noted C-section as mode of birth and/or included an ICD code for C-section, and/or if the woman was registered in the Surgery Database as having delivered via $\mathrm{C}$-section. All other records were included as vaginal births.

Socioeconomic position was defined on the basis of occupation of the woman giving birth. Occupation was registered in nine categories, which we summarized into four categories as follows: housewives (housewife, unemployed), small business (small business, casual laborer, farmer), professional (professional, government employee, private employee), and student (student/ pupil). Maternal age was registered in years and categorised as follows: < 16, 16-20, 21-25, 26-30, 31-35, $36-40$, and $>40$ years.

The Robson classification has been developed to compare C-section rates across hospitals, and provides a starting point for accessing hospital-based C-section rates. To categorize women according to the Robson classification [13], we used information on parity, gestational age (in weeks), presentation (cephalic/ breech/ other non-cephalic presentation), number of fetuses, and previous C-section (yes/no) from the Delivery Database. As we had no information on spontaneous vs. induced labor, we used an adapted version of the Robson classification (see Table 6). 2845 women (23\%) could not be classified into a Robson category because of missing information on gestational age. We developed two additional groups (Group 11: All nulliparous women, singleton cephalic, gestational age unknown; Group 12: All multipara, singleton cephalic, gestational age unknown) to address this problem.

Finally, parity was not always consistently recorded sometimes as parity before birth, sometimes as parity after birth. As the proportion of women with parity recorded as zero led to an implausibly low estimate of the proportion of nulliparous women (5.5\%), we included all women with parity recorded as zero or one as nulliparous, which might have led to an over-estimation of nulliparous women and a dilution of the effect of parity on mode of birth.

For each woman, we determined whether she had an indication for C-section according to the clinical guidelines of the hospital [14]. We obtained these guidelines from the maternity department and translated these into ICD codes and other information necessary to determine C-section indication. Table S1 provides a full overview of the hospital guidelines, information necessary and information available to determine clinical indication posthoc. We used the ICD codes and other information in the Delivery and Surgery Databases to determine if a woman had a C-section indication according to the guidelines. The information in the databases was not always detailed enough to conclusively determine if a woman had a clinical indication. For example, fetal anomaly incompatible with spontaneous vertex birth (SVB) is a C-section indication according to the hospital guidelines. An ICD code for foetal abnormality exists, but this does not clarify whether the anomaly was incompatible with SVD. As another example, previous Csection is an indication for $\mathrm{C}$-section according to the hospital guidelines in the case of two or more previous $\mathrm{C}$-sections. The ICD codes contained whether a woman had previous C-section, but did not provide details on the number of previous $\mathrm{C}$-sections. In such cases, where part of the information was missing, we used the precautionary principle and assumed that the woman had a Csection indication. For comparative purposes, we also determined for each woman if she had a C-section indication when using the Kenyan national guidelines [15, 16], the Dutch [17-24] and English [25-29] guidelines.

\section{Analyses}

First, we calculated the C-section rate for the total population and by socioeconomic position and other background characteristics. Then, we calculated the percentage of women with $\mathrm{C}$-section indication and examined the determinants of $\mathrm{C}$-section indication using logistic regression analysis. Next, we calculated the Csection rate among women with and without $\mathrm{C}$-section indication and the percentage of C-section deliveries without clinical indication. Then, we examined determinants of C-section using logistic regression analysis. Using multivariable logistic regression analyses, we examined if socioeconomic inequalities in the odds of Csection were explained by differences in medical need for a C-section (defined as C-section indication according to the hospital guidelines), previous $\mathrm{C}$-section, maternal age and parity. We also divided the population into the Robson groups, and examined if there were socioeconomic inequalities in $\mathrm{C}$-section rate within Robson groups. We analyzed the data using Stata 13 (Stata, College Station, TX, USA).

\section{Results}

In 2014, 12,209 women gave birth in the hospital (Table 1). Most women (58\%) were housewives; a minority $(11 \%)$ had a professional occupation. Professional women tended to be older than women of other socioeconomic groups. Nearly $50 \%$ of women had a parity of 0 or 1 , while parity above four was rare, especially among students and professionals. Previous C-sections were more common among professionals than in other socioeconomic groups. Only a tiny fraction (1\%) of women were referral patients.

The C-section rate was $16.5 \%$, varying from $21.1 \%$ among professionals to $15.8 \%$ among housewives, and $13.8 \%$ among students. The rate increased with maternal 
Table 1 Distribution of the study population by background characteristics, and C-section rate by background characteristics

\begin{tabular}{|c|c|c|c|c|c|c|c|c|c|}
\hline & \multicolumn{7}{|c|}{ Distribution of the study population by background characteristics } & \multirow{2}{*}{\multicolumn{2}{|c|}{$\begin{array}{l}\text { C-section rates by } \\
\text { background } \\
\text { characteristics }\end{array}$}} \\
\hline & \multicolumn{2}{|c|}{ Total $(n=12,209)$} & \multirow{2}{*}{$\begin{array}{l}\text { Housewife } \\
\%\end{array}$} & \multirow{2}{*}{$\begin{array}{l}\text { Small business } \\
\%\end{array}$} & \multirow{2}{*}{$\begin{array}{l}\text { Professional } \\
\% \\
\end{array}$} & \multirow{2}{*}{$\begin{array}{l}\text { Student } \\
\% \\
\end{array}$} & \multirow{2}{*}{$\begin{array}{l}\text { Missing } \\
\%\end{array}$} & & \\
\hline & $\mathrm{n}$ & $\%$ & & & & & & $\mathrm{n}$ & $\%$ \\
\hline \multicolumn{10}{|c|}{ Characteristics of the mother } \\
\hline All deliveries ${ }^{a}$ & 12,209 & 100 & & & & & & 2020/12209 & 16.5 \\
\hline \multicolumn{10}{|l|}{ Occupation } \\
\hline Housewife & 7129 & 58 & & & & & & $1125 / 7129$ & 15.8 \\
\hline Small business & 2161 & 18 & & & & & & $398 / 2161$ & 18.4 \\
\hline Professional & 1304 & 11 & & & & & & 275/1304 & 21.1 \\
\hline Student & 1375 & 11 & & & & & & $190 / 1375$ & 13.8 \\
\hline Missing & 240 & 2 & & & & & & $32 / 240$ & 13.3 \\
\hline \multicolumn{10}{|l|}{ Age of mother } \\
\hline$<16$ years & 61 & 1 & 0 & 0 & 0 & 3 & 1 & $8 / 61$ & 13.1 \\
\hline $16-20$ years & 2081 & 17 & 17 & 9 & 4 & 41 & 19 & 273/2081 & 13.1 \\
\hline $21-25$ years & 4437 & 36 & 38 & 32 & 27 & 46 & 38 & $623 / 4437$ & 14 \\
\hline 26-30 years & 3373 & 28 & 28 & 33 & 40 & 8 & 27 & $617 / 3373$ & 18.3 \\
\hline $31-35$ years & 1452 & 12 & 11 & 16 & 18 & 2 & 12 & $318 / 1452$ & 21.9 \\
\hline $36-40$ years & 656 & 5 & 5 & 8 & 10 & 0 & 3 & $145 / 656$ & 22.1 \\
\hline$>40$ years & 124 & 1 & 1 & 2 & 1 & 0 & 0 & $34 / 124$ & 27.4 \\
\hline Missing & 25 & 0 & 0 & 0 & 0 & 0 & 1 & $2 / 25$ & 8 \\
\hline \multicolumn{10}{|l|}{ Parity ${ }^{b}$} \\
\hline $0-1$ & 5915 & 48 & 44 & 39 & 47 & 89 & 60 & $926 / 5915$ & 15.7 \\
\hline $2-3$ & 5564 & 46 & 49 & 54 & 49 & 11 & 37 & $976 / 5564$ & 17.5 \\
\hline$>4$ & 692 & 6 & 7 & 7 & 4 & 0 & 3 & $114 / 692$ & 16.5 \\
\hline Missing & 38 & 0 & 0 & 0 & 0 & 0 & 1 & $4 / 38$ & 10.5 \\
\hline \multicolumn{10}{|l|}{ Number of fetuses } \\
\hline Singleton & 11,726 & 96 & 96 & 96 & 96 & 96 & 95 & 1884/11726 & 16.1 \\
\hline Multiple gestation & 228 & 2 & 2 & 2 & 2 & 1 & 2 & $103 / 228$ & 45.2 \\
\hline Missing & 255 & 2 & 2 & 2 & 2 & 2 & 3 & & \\
\hline \multicolumn{10}{|l|}{ Previous C-section } \\
\hline No & 11,605 & 95 & 95 & 94 & 92 & 99 & 96 & $1419 / 11605$ & 12.2 \\
\hline Yes & 604 & 5 & 5 & 6 & 8 & 1 & 4 & $601 / 604$ & 99.5 \\
\hline \multicolumn{10}{|l|}{ Referral patient } \\
\hline No & 12,000 & 98 & 98 & 98 & 99 & 99 & 99 & $1947 / 12000$ & 16.2 \\
\hline Yes & 209 & 2 & 2 & 2 & 1 & 1 & 1 & $73 / 209$ & 34.9 \\
\hline \multicolumn{10}{|c|}{ Antenatal Care Attended } \\
\hline No & 269 & 2 & 2 & 2 & 3 & 2 & 7 & $40 / 269$ & 14.9 \\
\hline Yes & 11,940 & 98 & 98 & 98 & 98 & 98 & 93 & 1980/11940 & 16.6 \\
\hline \multicolumn{10}{|c|}{ Characteristics of the infant } \\
\hline \multicolumn{10}{|c|}{ Position fetus } \\
\hline Cephalic & 11,883 & 97.3 & 98 & 97 & 97 & 98 & 98 & $1743 / 11883$ & 14.7 \\
\hline
\end{tabular}

\section{Characteristics of the infant}

Position fetus

$\begin{array}{lllllllll}11,883 & 97.3 & 98 & 97 & 97 & 98 & 98 & 1743 / 11883 & 14.7 \\ 253 & 2.1 & 2 & 3 & 3 & 2 & 2 & 211 / 253 & 83.4 \\ 73 & 0.6 & 1 & 1 & 1 & 1 & 0 & 66 / 73 & 90.4\end{array}$

Gestational age (in weeks) 
Table 1 Distribution of the study population by background characteristics, and C-section rate by background characteristics (Continued)

\begin{tabular}{|c|c|c|c|c|c|c|c|c|c|}
\hline & \multicolumn{7}{|c|}{ Distribution of the study population by background characteristics } & \multirow{2}{*}{\multicolumn{2}{|c|}{$\begin{array}{l}\text { C-section rates by } \\
\text { background } \\
\text { characteristics }\end{array}$}} \\
\hline & \multicolumn{2}{|c|}{ Total $(n=12,209)$} & \multirow{2}{*}{$\begin{array}{l}\text { Housewife } \\
\%\end{array}$} & \multirow{2}{*}{$\begin{array}{l}\text { Small business } \\
\%\end{array}$} & \multirow{2}{*}{$\begin{array}{l}\text { Professional } \\
\%\end{array}$} & \multirow{2}{*}{$\begin{array}{l}\text { Student } \\
\%\end{array}$} & \multirow{2}{*}{$\begin{array}{l}\text { Missing } \\
\%\end{array}$} & & \\
\hline & $n$ & $\%$ & & & & & & $\mathrm{n}$ & $\%$ \\
\hline Moderate to late preterm (32-36) & 1073 & 8.8 & 9 & 9 & 6 & 9 & 6 & 196/1073 & 18.3 \\
\hline Term $(>36)$ & 7725 & 63.3 & 62 & 64 & 70 & 63 & 66 & $1302 / 7725$ & 16.9 \\
\hline Missing & 3170 & 26 & 27 & 26 & 22 & 25 & 25 & $479 / 3170$ & 15.1 \\
\hline \multicolumn{10}{|l|}{ Birthweight singletons (11,726 infants) } \\
\hline Very low (650-1499) & 196 & 1.7 & 2 & 2 & 1 & 2 & 3 & 29/196 & 14.8 \\
\hline Low (1500-2499) & 1070 & 9.1 & 9 & 9 & 7 & 12 & 9 & 206/1070 & 19.3 \\
\hline Normal (2500+) & 10,148 & 86.5 & 87 & 86 & 90 & 84 & 80 & $1592 / 10148$ & 15.7 \\
\hline Missing & 312 & 2.7 & 2 & 3 & 2 & 3 & 8 & $57 / 312$ & 18.3 \\
\hline \multicolumn{10}{|c|}{ Birthweight multiple gestation (419 infants in 228 births) } \\
\hline Very low (650-1499) & 46 & 11.0 & 11 & 12 & 21 & 3 & 13 & $8 / 46$ & 17.4 \\
\hline Low (1500-2499) & 212 & 50.6 & 47 & 59 & 47 & 72 & 13 & $103 / 212$ & 48.6 \\
\hline Normal (2500+) & 161 & 38.4 & 42 & 29 & 32 & 24 & 88 & $69 / 161$ & 42.9 \\
\hline
\end{tabular}

${ }^{\mathrm{a}}$ Fetuses with a birthweight $<650 \mathrm{~g}$ were excluded

${ }^{b}$ Parity was not always consistently recorded - sometimes as parity before delivery, sometimes as parity after delivery. Therefore, we combined into one category women with parity recorded as zero and women with parity recorded as one

age, from $13 \%$ in the $\leq 20$ years groups to over $27 \%$ in the $>40$ years group. Among women with a previous Csection, C-section was nearly universal (99\%).

The prevalence of clinical indication for C-section was highest among professionals (16\% of all births among professionals) and lowest among students (9\%), with housewives being in-between (11\%) (Table 2). The higher odds of indication in professionals compared with housewives (OR 1.48; 95\%CI 1.25-1.75) was largely explained by maternal age, parity, and previous C-section (aOR 1.17; 95\%CI $0.93-1.48$ ), and only by previous Csection when professionals were compared with students (Table S2).

Nearly all women with a C-section indication gave birth accordingly, irrespective of socioeconomic position (Table 3). There were small differences in unmet need: $2.4 \%$ of housewives with a C-section indication had a vaginal birth, compared with $1 \%$ among professionals. Over-use according to hospital guidelines was somewhat higher among professionals than among housewives: among births without $\mathrm{C}$-section indication, $6.6 \%$ (professionals) and 5.5\% (housewives) respectively ended up with a $\mathrm{C}$-section.

For around $30 \%$ of C-sections there was no Csection indication (Table 4); this was similar (27\% [13/49]) in our review of manual patient files. Previous $\mathrm{C}$-section as indication accounted for $30 \%$ of Csections $(22 \%$ when considering previous $\mathrm{C}$-section as only indication, $30 \%$ when also including multiple indications that included previous C-section). This proportion was higher among professionals (37\% when including multiple indications) than among housewives (31\%).

The higher C-section rate among professionals compared with other socioeconomic groups was mostly due to higher medical need, while over-use based on hospital guidelines only contributed a little: the C-section rate among professionals (21.5\%) was built up of $15.6 \%$ indicated C-sections plus 5.5\% not indicated C-sections (of all births), compared with 10.9\% indicated plus 4.9\% non-indicated C-sections among housewives (Fig. 1a). In other words, the $\mathrm{C}$-section rate difference between professionals and housewives of 5.3 percentage points (pp) was for $4.7 \mathrm{pp}$. due to indicated C-sections. These patterns were similar when using the Kenyan, Dutch and English guidelines (Table S3). The $\mathrm{C}$-section rate difference of $4.7 \mathrm{pp}$. due to indicated C-sections consisted for $2.9 \mathrm{pp}$. of indication related to previous Csections (Fig. 1b).

The odds of a C-section were 1.43 (95\%CI 1.23-1.65) times higher among professionals compared with housewives (1.67 [95\%CI $1.36-2.04]$ times higher compared with students) (Table 5 and Table S4). The higher Csection rate among professionals compared with housewives was not explained by multiple births, presentation, or gestational age. It was substantially explained by $\mathrm{C}$ section indication, previous $\mathrm{C}$-section, maternal age, and parity. The combination of the above variables nearly fully explained the higher $\mathrm{C}$-section rate among professionals compared with housewives (aOR 1.08; 95\%CI 
Spec et al. International Journal for Equity in Health

(2020) 19:117

Page 6 of 14

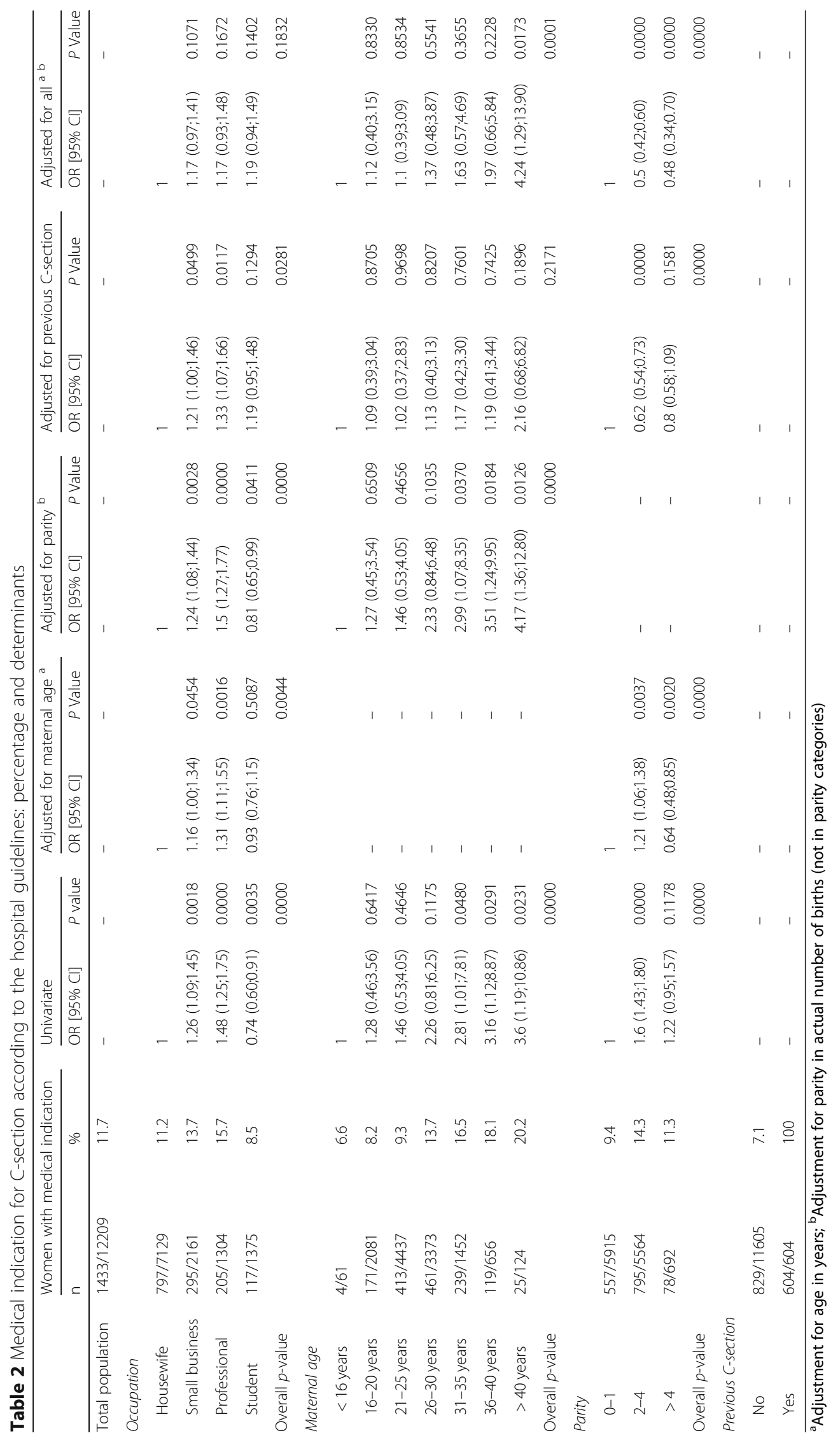


Table 3 C-section and vaginal delivery rate among women with and without clinical indication

\begin{tabular}{|c|c|c|c|c|c|c|}
\hline & \multicolumn{2}{|c|}{$\begin{array}{l}\text { C-section rate among women with } \\
\text { indication }\end{array}$} & \multicolumn{2}{|c|}{$\begin{array}{l}\text { Vaginal delivery rate among women with } \\
\text { indication }\end{array}$} & \multicolumn{2}{|c|}{$\begin{array}{l}\text { C-section rate among women without } \\
\text { indication }\end{array}$} \\
\hline & $n$ & $\%$ & $n$ & $\%$ & $n$ & $\%$ \\
\hline Total population & $1404 / 1433$ & 98.0 & $29 / 1433$ & 2.0 & $616 / 10776$ & 5.7 \\
\hline Housewife & $778 / 797$ & 97.6 & $19 / 797$ & 2.4 & $347 / 6332$ & 5.5 \\
\hline Small business & $291 / 295$ & 98.6 & $4 / 295$ & 1.4 & $107 / 1866$ & 5.7 \\
\hline Professional & $203 / 205$ & 99.0 & $2 / 205$ & 1.0 & $72 / 1099$ & 6.6 \\
\hline Student & $115 / 117$ & 98.3 & $2 / 117$ & 1.7 & $75 / 1258$ & 6.0 \\
\hline
\end{tabular}

0.83-1.40). Previous C-sections explained the higher $\mathrm{C}$ section rate among professionals compared with students.

The combined Robson groups $1+2$ and Robson group 5 contributed most to the overall $\mathrm{C}$-section rate and to the difference in $\mathrm{C}$-section rate between professionals and housewives (Table 6). The higher C-section rate among professionals (17\%) compared with other women (13\% among housewives) in Robson groups $1+2$ (nulliparous women with a full-term pregnancy of a singleton in cephalic presentation) is noteworthy. Differences -albeit smaller- were also observed for Groups 3+4 (multiparous women without previous $\mathrm{C}$-section with a term singleton in cephalic presentation) (9.6\% vs $7.2 \%$ ). For other Robson groups the number of women in each SEP group was very small.

Also, when only considering women without a previous $\mathrm{C}$-section, $\mathrm{C}$-section rates were higher among professionals $(14.5 \%)$ than among other groups (housewives: $11.5 \%$, students $13.1 \%$ ) (Figure S1A), although these differences were smaller than in the total study population. Among women without previous C-section, the prevalence of indication was somewhat higher among professionals (9\%) than among housewives (7\%), which was for a large part explained by age and parity (Figure S1B-C). $43 \%$ of C-sections among women without previous $\mathrm{C}$-section were not medically indicated (Figure S1D); this was similar
(42\% [13/31]) in our review of manual patient files. Almost one third of the three pp. difference in Csection rate between professionals and housewives was due to medically non-indicated $\mathrm{C}$-sections (Figure $\mathrm{S} 1 \mathrm{~B})$. The higher odds of $\mathrm{C}$-section among professionals compared with housewives (OR 1.3; 95\%CI 1.09-1.56) was largely explained by the combination of indication, age and parity (aOR 1.03; 95\%CI $0.83-$ 1.28) (Figure S1E).

\section{Discussion \\ Main findings}

Our study shows that unnecessary primary C-sections and near universal repeat $\mathrm{C}$-sections play an important role in explaining both the overall $\mathrm{C}$-section rate and socioeconomic inequalities in $\mathrm{C}$-section. Socioeconomic inequalities in $\mathrm{C}$-section were moderate in the Kenyan referral hospital that we studied. These inequalities were foremost explained by a higher level of indicated C-sections -mostly related to previous $\mathrm{C}$-section- among high SEP women. Nearly all women with a previous C-section had a repeat $\mathrm{C}$-section for their subsequent pregnancy, and 3 in $10 \mathrm{C}$ sections had previous $\mathrm{C}$-section as indication. But overuse of C-sections based on hospital guidelines was also substantial, and seen in all socioeconomic groups: over 4 in 10 primary $\mathrm{C}$-sections had no documented indication. Higher over-use among high SEP women explained around one third of socioeconomic inequalities in primary $\mathrm{C}$-sections. Socioeconomic differences in age and parity

Table 4 Distribution of C-section deliveries according to indication

\begin{tabular}{|c|c|c|c|c|c|c|c|c|c|c|c|c|c|c|c|c|}
\hline & \multicolumn{2}{|c|}{$\begin{array}{l}\text { \% with no C- } \\
\text { section } \\
\text { indication }\end{array}$} & \multicolumn{2}{|c|}{$\begin{array}{l}\% \text { with only } \\
\text { previous C- } \\
\text { section as } \\
\text { indication }\end{array}$} & \multicolumn{2}{|c|}{$\begin{array}{l}\% \text { with multiple } \\
\text { indications } \\
\text { including PCS }\end{array}$} & \multicolumn{2}{|c|}{$\begin{array}{l}\% \text { with only } \\
\text { foetal distress } \\
\text { as indication }\end{array}$} & \multicolumn{2}{|c|}{$\begin{array}{l}\text { \% with only } \\
\text { prolonged } \\
\text { labour as } \\
\text { indication }\end{array}$} & \multicolumn{2}{|c|}{$\begin{array}{l}\% \text { with other } \\
\text { indication }\end{array}$} & \multicolumn{2}{|c|}{$\begin{array}{l}\text { \% with } \\
\text { multiple } \\
\text { indications } \\
\text { excluding } \\
\text { PCS } \\
\end{array}$} & \multirow{2}{*}{$\begin{array}{l}\text { Total } \\
\text { n }\end{array}$} & \multirow[b]{2}{*}{$\%$} \\
\hline & $n$ & $\%$ & $n$ & $\%$ & $n$ & $\%$ & $n$ & $\%$ & $n$ & $\%$ & $n$ & $\%$ & $n$ & $\%$ & & \\
\hline Total population & $616 / 2020$ & 30.5 & $451 / 2020$ & 22.3 & $150 / 2020$ & 7.4 & $245 / 2020$ & 12.1 & $332 / 2020$ & 16.4 & $145 / 2020$ & 7.2 & $81 / 2020$ & 4 & 2020 & 100 \\
\hline Housewife & $347 / 1125$ & 30.8 & $265 / 1125$ & 23.6 & $81 / 1125$ & 7.2 & $127 / 1125$ & 11.3 & $174 / 1125$ & 15.5 & $86 / 1125$ & 7.6 & $45 / 1125$ & 4 & 1125 & 100 \\
\hline Small business & $107 / 398$ & 26.9 & $94 / 398$ & 23.6 & $40 / 398$ & 10.1 & $52 / 398$ & 13.1 & $62 / 398$ & 15.6 & 29/398 & 7.3 & $14 / 398$ & 3.5 & 398 & 100 \\
\hline Professional & $72 / 275$ & 26.2 & $78 / 275$ & 28.4 & $23 / 275$ & 8.4 & $36 / 275$ & 13.1 & $39 / 275$ & 14.2 & $19 / 275$ & 6.9 & $8 / 275$ & 2.9 & 275 & 100 \\
\hline Student & 75/190 & 39.5 & $7 / 190$ & 3.7 & $4 / 190$ & 2.1 & 28/190 & 14.7 & $54 / 190$ & 28.4 & $11 / 190$ & 5.8 & $11 / 190$ & 5.8 & 190 & 100 \\
\hline
\end{tabular}




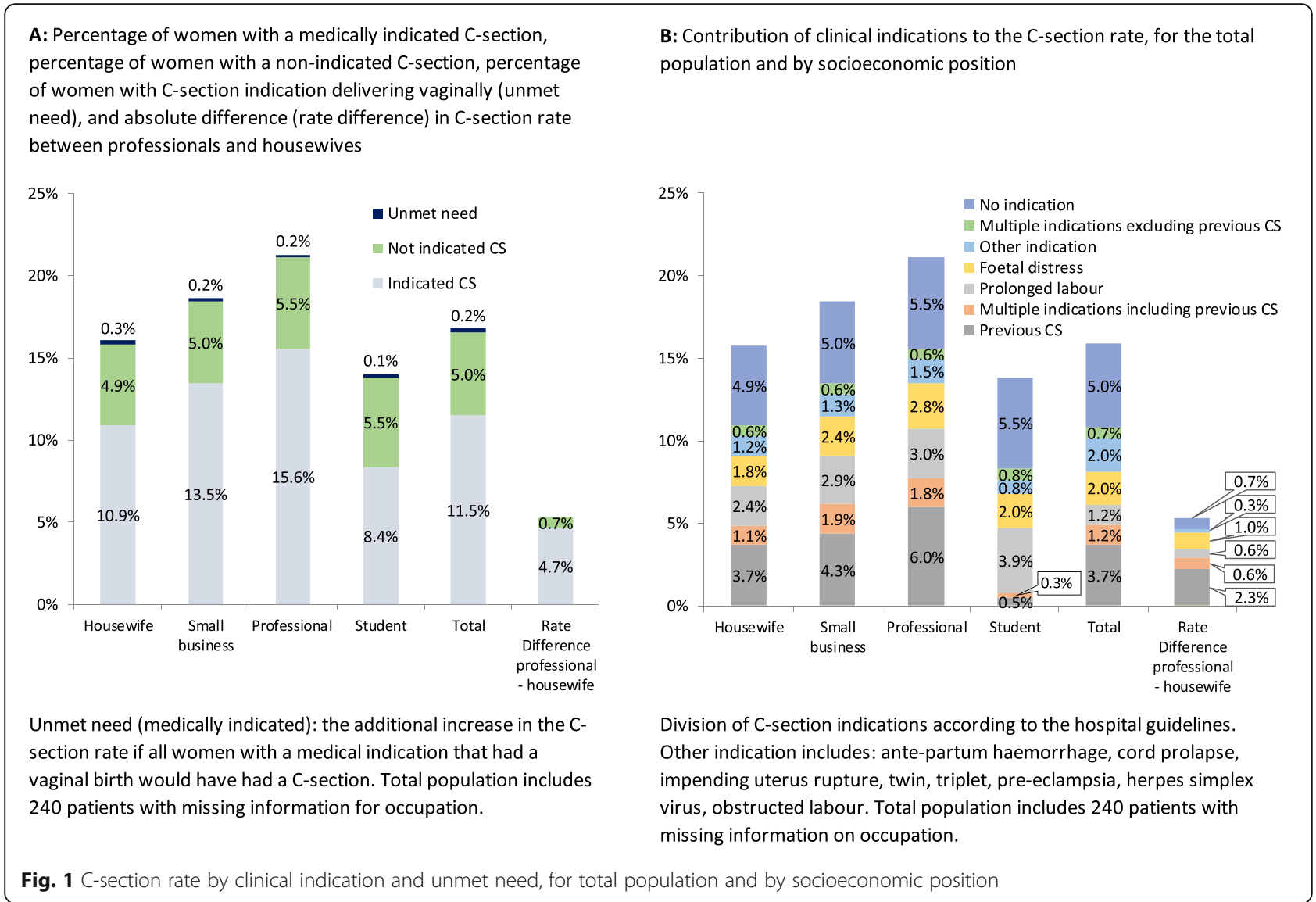

further contributed to explaining inequalities in indicated and unindicated $\mathrm{C}$-sections. Our study suggests that prevention of unnecessary primary $\mathrm{C}$-sections and promotion of safe trial of labor with close monitoring in women with a scarred uterus could help curb the $\mathrm{C}$-section epidemic and help reduce socioeconomic differences in $\mathrm{C}$-section.

\section{Strengths and limitations}

Our analyses suffered from some problems. First, we used anonymised versions of the Delivery and Surgery Databases, which complicated patient identification and linking of the databases due to typos in patient numbers. $286 \mathrm{C}$-section records in the Delivery Database (2\% of all deliveries, $13.2 \%$ of $\mathrm{C}$-section deliveries) could not be matched to a Surgery Database record, and $148 \mathrm{C}$-section records in the Surgery Database ( $1 \%$ of all deliveries, $6.8 \%$ of C-sections) could not be matched to a Delivery Database record. To avoid over-estimating the $\mathrm{C}$-section rate, we used the Delivery Database as basis for our analyses, rather than including all unlinked records. If we also had included the 148 unlinked records from the Surgery Database, the C-section rate would have been $17.1 \%$ instead of $16.5 \%$.
Secondly, the analyses suffered from some uncertainty in determining clinical indication for Csection because only a limited set of variables was available in the electronic databases. Our use of the precautionary principle, as explained in the methods section, will probably have led to an overestimation of the proportion of caesarean deliveries with an indication. Importantly, multiple previous $\mathrm{C}$-sections constituted a $\mathrm{C}$-section indication according to the hospital guidelines, while information on the number of previous $\mathrm{C}$-sections missed in the electronic records. Use of the precautionary principle led to the classification of all previous $\mathrm{C}$-sections as indication, while many will have been first repeats. Also, we were not able to take into account clinical judgement not recorded in the electronic database. This may have led both to an under-estimation or overestimation of the proportion of caesarean deliveries with a clinical indication. Detailed analysis of a random selection of the full manual files of $\mathrm{C}$-section patients confirms our estimate of C-section overuse. Furthermore, there is no indication that an over- or underestimation of clinical indication for C-section would be differential by SEP. 


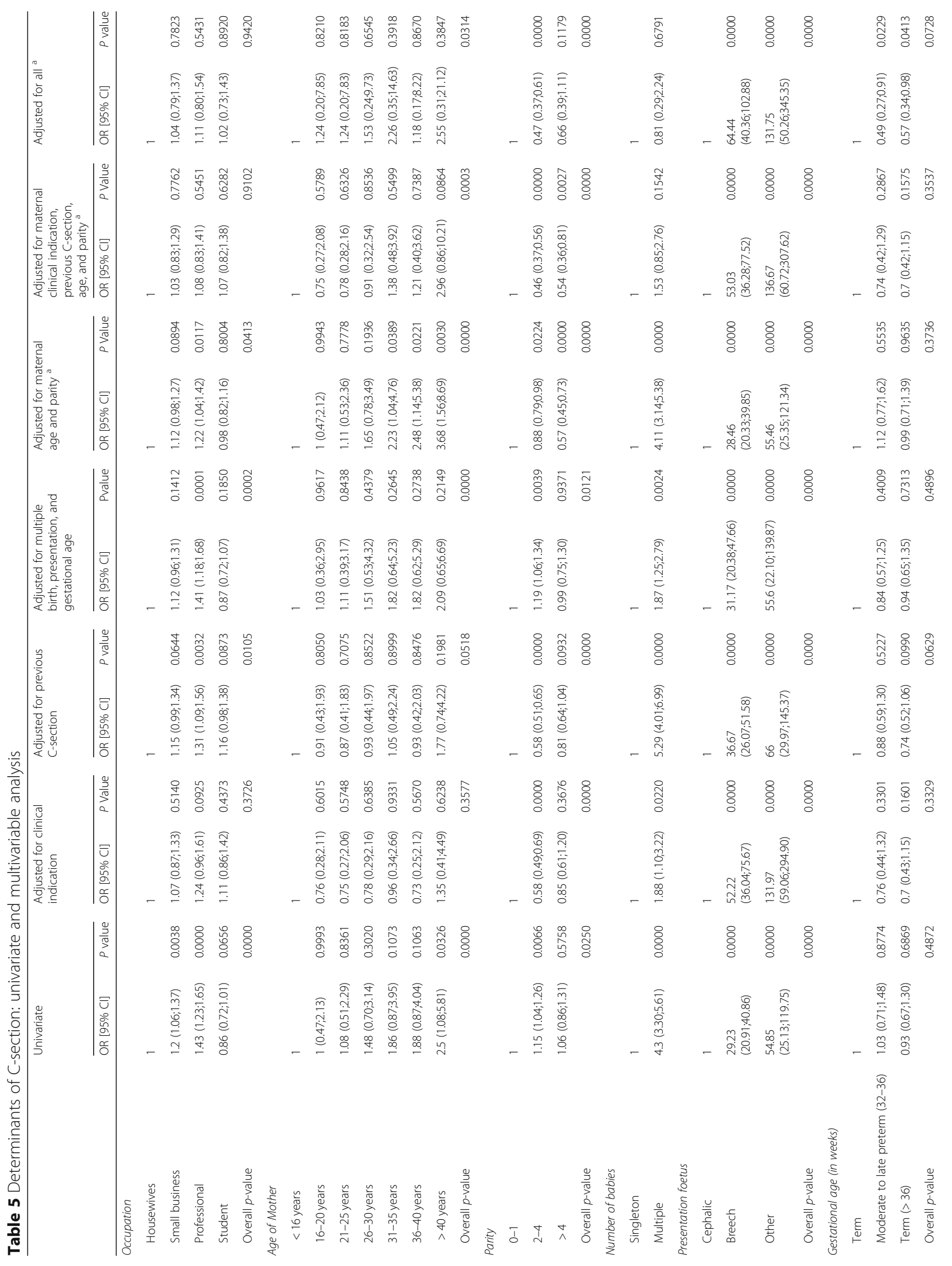




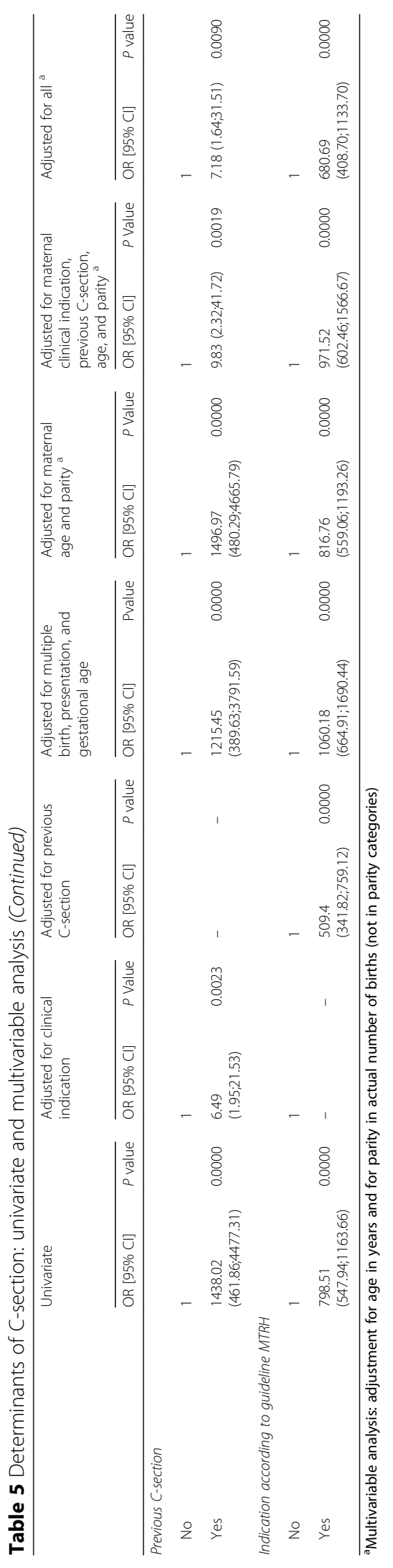




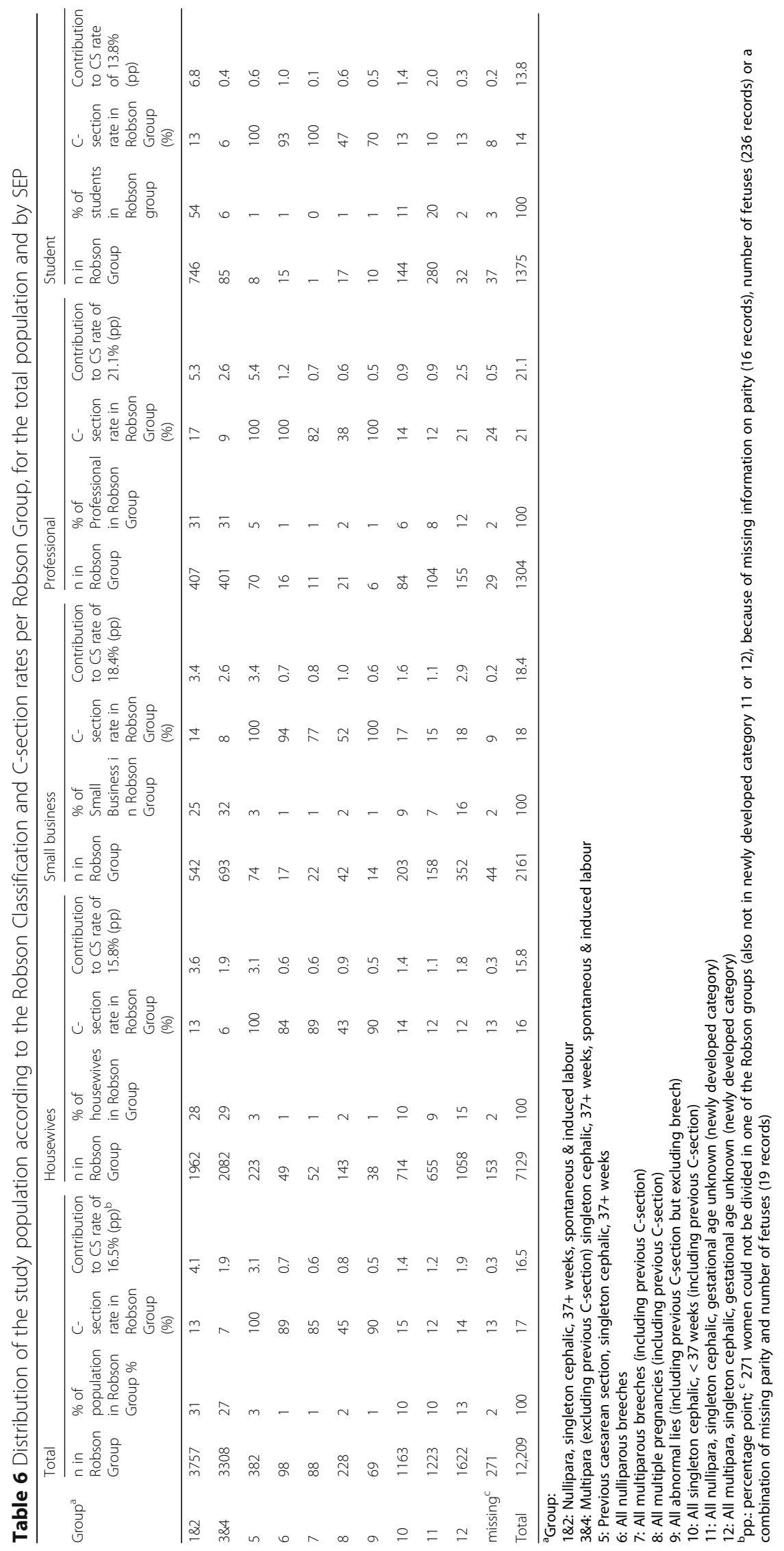


Finally, maternal occupation as recorded in the patient files is a rough proxy for SEP, arguably with measurement error both in determining occupation itself and in classifying occupation into categories. There is no indication that such measurement error was systematic. Combined with the broad occupational categories used, random measurement error in occupational class will have led to an underestimation of socioeconomic differences in $\mathrm{C}$-section rate.

\section{Generalizability}

Our findings pertain to an academic referral hospital and are not generalizable to Kenya at large, where nearly $40 \%$ of women have home births and, consequently, C-section rates at the population level are lower [4]. Socioeconomic differences in C-section rates are much larger in Kenya at large, as they partly capture socioeconomic differences in facility birth. Yet, the $\mathrm{C}$-section rate in our study hospital was comparable to the institutional $\mathrm{C}$-section rate in Kenya as a whole [4]. Given that the hospital draws on a broad catchment population, and that only a tiny proportion of women used the hospital as referral hospital, one might see our findings as a precursor of what may happen in the rest of Kenya -and arguably other low and middle income countrieswhen facility birth rates increase further, especially when repeat $\mathrm{C}$-sections are highly common. At the same time, the $\mathrm{C}$-section rate in our study hospital was still modest compared with those observed in some countries where population-level C-section rates reach up to $40-60 \%$ [30]. In such countries, the contribution of unnecessary primary C-sections to (inequalities in) the $\mathrm{C}$-section rate will be much larger than in our study.

\section{Research implications}

First, our study shows that a combination of criterionbased auditing and equity analysis can help gain a better understanding of drivers of $\mathrm{C}$-section rates and inequalities in these rates - a first step to curb increasing over-use. Our study of over 12,000 births was only practically feasible because of the availability of electronic patient records. Electronic records can facilitate monitoring, and our study shows the potential for using hospital record data for improvements in health care delivery. At the same time, a more detailed documentation of decisions around mode of birth, including if Csection was on demand, is advisable for accountability purposes and to improve quality of care. Second, our study shows that socioeconomic differences in $\mathrm{C}$ section rates, especially in contexts of moderate $\mathrm{C}$ section rates and near universal repeat $\mathrm{C}$-sections, can be largely explained by differences in medical indication (largely due to previous C-section), age and parity. This should be taken into account in future explanatory research on socioeconomic differences in $\mathrm{C}$-section rates. Third, qualitative research on decisions around primary $\mathrm{C}$-sections, both in the context of moderate $\mathrm{C}$-section rates as in Kenya, as in the context of very high $\mathrm{C}$ section rates such as for example Colombia, will be important to understand demand and supply side mechanisms that drive over-use. Finally, future research should address the paucity of evidence on how to safely and effectively reduce primary and repeat C-section rates in resource poor countries [31].

\section{Policy implications}

Our findings suggest that unnecessary primary Csections, combined with a practice of near universal repeat $\mathrm{C}$-sections fuel the $\mathrm{C}$-section epidemic. Unnecessary primary $\mathrm{C}$-sections cause needless maternal and infant morbidity $[5-8,32]$. The incidence of uterus rupture in women with a prior C-section, for example, is $1 \%$ in resource-poor countries [33]. Unnecessary primary $\mathrm{C}$-sections combined with near universal repeat $\mathrm{C}$-sections lead to a cascade of $\mathrm{C}$ sections. Our finding that repeat $\mathrm{C}$-sections substantially contribute to (inequalities in) the $\mathrm{C}$-section rate correspond Vogel et al.'s conclusions that repeat Csection are an increasingly important driver of Csection rates in low- and middle-income countries [34]. We add that they are also an important driver of socioeconomic inequalities in $\mathrm{C}$-section rates.

Little is known about how to effectively reduce unnecessary primary $\mathrm{C}$-sections in low and middle income countries $[35,36]$. Some evidence suggests that audit and feedback can reduce C-section rates [37] and that this is feasible in Sub-Saharan African contexts [38]. Changes in financial incentives for hospitals and doctors in combination with better pain relief and support during labor may also be effective [39]. Furthermore, investments in training and equipment for assisted vaginal birth, especially vacuum extraction, can reduce Csection rates in case of prolonged second stage labor or foetal distress [40]. While assisted vaginal birth is associated with reductions in morbidity and mortality, especially in resource-poor countries [40], such births remain rare in these settings [41]. Promoting safe trial of labor with close monitoring in women with a scarred uterus can reduce the prevalence of repeat $\mathrm{C}$-sections, although high-quality evidence on the benefits and harms of vaginal birth after $\mathrm{C}$-section remains scarce $[42,43]$. Prevention of unnecessary primary C-sections and promoting safe trial of labor should be part of broader efforts to improve quality of maternity care, which should include shared decision making [44]. 


\section{Conclusions}

Higher C-section rates among better-off women can be partly explained by unnecessary primary $\mathrm{C}$-sections and by higher supposed medical need due to previous $\mathrm{C}$ section. Prevention of unnecessary primary C-sections and promoting safe trial of labor with close monitoring in women with a scarred uterus should be a priority in addressing over-use of C-section.

\section{Supplementary information}

Supplementary information accompanies this paper at https://doi.org/10. 1186/s12939-020-01215-2.

Additional file 1: Table S1. Main indication, sub-indications and information required to judge clinical indication for C-section. Main indications and required information are displayed in ICD-codes (ICD-10).

Table S2. The odds of medical indication for C-section according to the hospital guidelines (Students instead of Housewives as reference category). Table S3. Mode of delivery according to indication for C-section. Table S4. Socioeconomic inequalities (measured in odds ratios) in Csection rate, without and with adjustment for clinical indication for Csection, previous C-section, multiple birth, presentation, gestational age, maternal age, and parity (Students compared with other socioeconomic groups). Figure S1. Women without previous C-section.

\section{Acknowledgements}

We would like to thank Dr. Elkanah Omenge Orang'o, Chair of the Department of Reproductive Health, Moi University School of Medicine, for his support of this study and Dr. Phillip Tonui for his contribution to the application of this study to Moi University Institutional Research and Ethics Committee, Eldoret, Kenya. We also would like to thank Mr. Richard Ole Kuyo, head, and Mr. Henry Ruiru Mwangi and Mr. Mainard Shikanga of the record department at Moi Teaching and Referral Hospital, Eldoret, Kenya for helping out retrieving the manual files from the library and getting access to the digital databases.

\section{Authors' contributions}

TAJH and PM conceived of the study. TAJH, PM, LvdS, and SL designed the study with support of TVdA and HM. LvdS and SL collected the data with support of PM and HM. LvdS, SL, and TAJH analyzed the data. LVdS, SL, TAJH, PM, HM, and TvdA interpreted the data. TAJH wrote a first draft of the manuscript. All authors contributed to the manuscript revisions and agreed with this latest version being submitted for publication.

\section{Funding}

TAJH was supported by an Erasmus University Rotterdam Research Excellence Initiative Grant. SS and LvdS were supported by the Rotary Clubs in Gouda, Gouda-Bloemendaal and Capelle aan den IJssel (The Netherlands).

\section{Availability of data and materials}

The data that support the findings of this study are available from the study hospital but restrictions apply to the availability of these data, and so are not publicly available. Data are however available from the authors upon reasonable request and with permission of the study hospital.

\section{Ethics approval}

Ethical permission was given on 9th of May, 2017 by the Institutional Research and Ethics Committee (IREC) of Moi University College of Health Sciences / Moi Teaching and Referral Hospital Institutional Research and Ethics Committee (reference: IREC/2017/27).

\section{Consent for publication}

Not applicable.

\section{Competing interests}

$\mathrm{HM}$ worked during the study as an obstetrician and gynaecologist in the study hospital.

\section{Author details}

${ }^{1}$ Department of Public Health, Erasmus MC, University Medical Center Rotterdam, Rotterdam, The Netherlands. ${ }^{2}$ Department of Reproductive Health, Moi University School of Medicine and Gynocare Womens and Fistula Hospital, Eldoret, Kenya. ${ }^{3}$ Department of Obstetrics and Gynaecology, Leiden University Medical Center, Leiden, The Netherlands. ${ }^{4}$ Athena Institute, Vrije Universiteit Amsterdam, Amsterdam, The Netherlands. ${ }^{5}$ School of Public Health, Moi University, Eldoret, Kenya.

Received: 4 February 2020 Accepted: 10 June 2020

Published online: 08 July 2020

\section{References}

1. Betran AP, Ye J, Moller AB, Zhang J, Gulmezoglu AM, Torloni MR. The increasing trend in caesarean section rates: global, regional and National Estimates: 1990-2014. PLoS One. 2016;11(2):e0148343.

2. Ronsmans C, Holtz S, Stanton C. Socioeconomic differentials in caesarean rates in developing countries: a retrospective analysis. Lancet. 2006; 368(9546):1516-23.

3. Boerma T, Ronsmans C, Melesse DY, et al. Global epidemiology of use of and disparities in caesarean sections. Lancet. 2018;392(10155):1341-8.

4. Kenya National Bureau of Statistics, Ministry of Health/Kenya, National AIDS Control Council/Kenya, Kenya Medical Research Institute, National Council for Population and Development/Kenya, ICF International. Kenya Demographic and Health Survey 2014. Rockville: Kenya National Bureau of Statistics, Ministry of Health/Kenya, National AIDS Control Council/Kenya, Kenya Medical Research Institute, National Council for Population and Development/Kenya, and ICF International; 2015.

5. Betran AP, Torloni MR, Zhang JJ, Gulmezoglu AM. Section WHOWGoC. WHO Statement on caesarean section rates. BJOG; 2015.

6. Human Reproduction Programme WHO. WHO statement on caesarean section rates. Geneva: WHO; 2015.

7. Souza JP, Gulmezoglu A, Lumbiganon P, et al. Caesarean section without medical indications is associated with an increased risk of adverse shortterm maternal outcomes: the 2004-2008 WHO global survey on maternal and perinatal health. BMC Med. 2010;8:71.

8. Keag OE, Norman JE, Stock SJ. Long-term risks and benefits associated with cesarean delivery for mother, baby, and subsequent pregnancies: systematic review and meta-analysis. PLoS Med. 2018;15(1):e1002494.

9. Stanton C, Ronsmans C. Baltimore group on C. recommendations for routine reporting on indications for cesarean delivery in developing countries. Birth. 2008;35(3):204-11.

10. Chu K, Cortier H, Maldonado F, Mashant T, Ford N, Trelles M. Cesarean section rates and indications in sub-Saharan Africa: a multi-country study from Medecins sans Frontieres. PLoS One. 2012;7(9):e44484.

11. World Health Organisation. International statistical classification of diseases and related health problems 10th revision. 5th ed. Geneva: World Health Organisation; 2016.

12. World Health Organization. International classification of procedures in medicine. Geneva: World Health Organization; 1976.

13. Robson M. Classification of caesarean sections. Fetal and Maternal Medicine Review. 2001;12(1):23-39.

14. MTRH Division of Reproductive Health. MTRH Division of Reproductive Health Protocol, 1st revision. Eldoret: MTRH Division of Reproductive Health Accessed; 2017.

15. Ministry of Public Health and Sanitation/Kenya MoMSK. National Guidelines for quality obstetrics and perinatal care. Nairobi: Ministry of Public Health and Sanitation and Ministry of Medical Services; 2012.

16. Ministry of Health/Kenya. Guidelines for prevention of mother to child transmission (PMTCT) of HIV/AIDS in Kenya. Nairobi: Ministry of Health/Kenya; 2012.

17. Nederlandse Vereniging voor Obstetrie \& Gynaecologie (NVOG). Stuitligging, Versie 2.0. 2008. https://richtlijnendatabase.nl/.

18. Nederlandse Vereniging voor Obstetrie \& Gynaecologie (NVOG). Indicatiestelling Sectio Caesarea, Versie 1.0. 2011. https://richtlijnendatabase.nl/.

19. Nederlandse Vereniging voor Obstetrie \& Gynaecologie (NVOG). Intrapartum foetale bewaking a terme. 2003. https://richtlijnendatabase.nl/.

20. Nederlandse Vereniging voor Obstetrie \& Gynaecologie (NVOG) Schouderdystocie. 2008. https://richtlijnendatabase.nl/.

21. Nederlandse Vereniging voor Obstetrie \& Gynaecologie (NVOG). Bloedverlies in de tweede helft zwangerschap (Versie 2.0). 2008. https:// richtlijnendatabase.nl/. 
22. Nederlandse Vereniging voor Obstetrie \& Gynaecologie (NVOG). Zwangerschap en bevalling na een voorgaande sectio caesarea, Versie 1.0 2010. https://richtlijnendatabase.nl/.

23. Nederlandse Vereniging voor Obstetrie \& Gynaecologie (NVOG). Meerlingzwangerschap. 2011. https://richtlijnendatabase.n//.

24. Nederlandse Vereniging voor Obstetrie \& Gynaecologie (NVOG). Modus partus bij placenta praevia marginalis (module) (Versie 2.0). 2015. https:// richtlijnendatabase.nl/.

25. National Collaborating Centre for Women's and Children's Health/Royal College of Obstetricians and Gynaecologists (RCOG). Caesarean Section. 2011. https://www.nice.org.uk/quidance/cg132/resources/caesarean-sectionpdf-35109507009733.

26. (RCOG) RCoOaG. Umbilical cord prolapse, Green-top Guideline No. 50. 2014 https://www.rcog.org.uk/globalassets/documents/guidelines/gtg-50umbilicalcordprolapse-2014.pdf.

27. Royal College of Obstetricians and Gynaecologists (RCOG). Placenta praevia, placenta praevia accreta and vasa praevia: Diagnosis and Management, Green-top Guideline No. 27. London: RCOG; 2011.

28. Royal College of Obstetricians and Gynaecologists (RCOG). Birth after previous caesarean birth, Green-top Guideline No. 45. October 20152015. https://www.rcog.org.uk/globalassets/documents/guidelines/gtg_45.pdf.

29. (NICE) NIfHaCE. Intrapartum care for healthy women and babies, Clinical Guideline. 2014. https://www.nice.org.uk/guidance/cg190/resources/ intrapartum-care-for-healthy-women-and-babies-pdf-35109866447557.

30. ICF. The DHS Program STATcompiler. Funded by USAID. 2015. http://www. statcompiler.com (Accessed 9 May 2019).

31. Khunpradit S, Tavender E, Lumbiganon P, Laopaiboon M, Wasiak J, Gruen RL. Non-clinical interventions for reducing unnecessary caesarean section. Cochrane Database Syst Rev. 2011;6:CD005528.

32. Sandall J, Tribe RM, Avery L, et al. Short-term and long-term effects of caesarean section on the health of women and children. Lancet. 2018 392(10155):1349-57.

33. Motomura K, Ganchimeg T, Nagata C, et al. Incidence and outcomes of uterine rupture among women with prior caesarean section: WHO multicountry survey on maternal and newborn health. Sci Rep. 2017:7:44093.

34. Vogel JP, Betran AP, Vindevoghel N, et al. Use of the Robson classification to assess caesarean section trends in 21 countries: a secondary analysis of two WHO multicountry surveys. Lancet Glob Health. 2015;3(5):e260-70.

35. Chen I, Opiyo N, Tavender E, et al. Non-clinical interventions for reducing unnecessary caesarean section. Cochrane Database Syst Rev. 2018;9:CD005528.

36. Betran AP, Temmerman M, Kingdon C, et al. Interventions to reduce unnecessary caesarean sections in healthy women and babies. Lancet. 2018; 392(10155):1358-68.

37. Boatin AA, Cullinane F, Torloni MR, Betrán AP. Audit and feedback using the Robson classification to reduce caesarean section rates: a systematic review. BJOG. 2018;125(1):36-42. https://doi.org/10.1111/1471-0528.14774.

38. Pirkle CM, Dumont A, Zunzunegui MV. Criterion-based clinical audit to assess quality of obstetrical care in low- and middle-income countries: a systematic review. Int J Qual Health Care. 2011;23(4):456-63.

39. Liu X, Lynch CD, Cheng WW, Landon MB. Lowering the high rate of caesarean delivery in China: an experience from Shanghai. BJOG. 2016;123(10):1620-8.

40. Nolens B, Capelle M, van Roosmalen J, et al. Use of assisted vaginal birth to reduce unnecessary caesarean sections and improve maternal and perinatal outcomes. Lancet Glob Health. 2019;7(4):e408-e9.

41. Bailey PE, van Roosmalen J, Mola G, Evans C, de Bernis L, Dao B. Assisted vaginal delivery in low and middle income countries: an overview. BJOG. 2017;124(9):1335-44

42. Kabore C, Chaillet N, Kouanda S, Bujold E, Traore M, Dumont A. Materna and perinatal outcomes associated with a trial of labour after previous caesarean section in sub-Saharan countries. BJOG. 2016;123(13):2147-55.

43. Dodd JM, Crowther CA, Huertas E, Guise JM, Horey D. Planned elective repeat caesarean section versus planned vaginal birth for women with a previous caesarean birth. Cochrane Database Syst Rev. 2013;12:CD004224.

44. Biraboneye SP, Ogutu O, van Roosmalen J, Wanjala S, Lubano K, Kinuthia J. Trial of labour or elective repeat caesarean delivery:are women making an informed decision at Kenyatta national hospital? BMC Pregnancy Childbirth. 2017;17(1):260

\section{Publisher's Note}

Springer Nature remains neutral with regard to jurisdictional claims in published maps and institutional affiliations.

\section{Ready to submit your research? Choose BMC and benefit from}

- fast, convenient online submission

- thorough peer review by experienced researchers in your field

- rapid publication on acceptance

- support for research data, including large and complex data types

- gold Open Access which fosters wider collaboration and increased citations

- maximum visibility for your research: over $100 \mathrm{M}$ website views per year

At $\mathrm{BMC}$, research is always in progress.

Learn more biomedcentral.com/submissions 